\section{Blueberry Cultivar Identification Using Random Amplified Polymorphic DNA and Sequence-characterized Amplified Region Markers}

\author{
Kang Hee Cho', Seo Jun Park, Su Jin Kim, Se Hee Kim, Han Chan Lee, \\ Mi Young Kim, and Jae An Chun \\ National Institute of Horticultural and Herbal Science, Rural Development \\ Administration, Wanju 55365, Korea
}

Additional index words. polymorphism, RAPD, SACR, specific primer, Vaccinium marker types have been applied to identify blueberry cultivars and analyze their genetic relationships (Aruna et al., 1995; Bian et al., 2014; Boches et al., 2006; Haghighi and Hancock, 1992; Levi and Rowland, 1997; Rowland and Dhanaraj, 2003). Among DNAbased markers, RAPD markers are easy, simple, and inexpensive to apply. The greatest advantage of the RAPD approach is its technical simplicity, paired with the independence of any prior DNA sequence information (Mu et al., 2012). RAPD markers have been used for the DNA fingerprinting of representative selections and cultivars of the three major commercially grown blueberry types (Aruna et al., 1995; Burgher et al., 2002; Levi and Rowland, 1997). The use of short primers and low annealing temperatures make RAPD markers extremely sensitive to slight changes in reaction conditions (Goulão et al., 2001); the use of RAPD has also been restricted in practical applications because of poor reproducibility and competitive priming (Li and Park, 2012; Williams et al., 1993). To overcome these problems, SCAR markers have been generated by cloning and sequencing RAPD fragments of interest and designing long primers complementary to the ends of the original RAPD fragments (Paran and Michelmore, 1993). The specificity and stability of RAPD markers can be greatly improved by their conversion into SCAR markers. SCAR markers have been used to identify the cultivars of many fruit species, including apple, grapevine, sweet cherry, and olive (Bautista et al., 2002; Hernández et al., 2001; Turkec et al., 2006; Vidal et al., 2000; Xu et al., 2001). In the present study, we developed a reliable PCRbased technique for the identification of blueberry cultivars.

\section{Materials and Methods}

Plant material and DNA extraction. A total of 45 blueberry cultivars, including 31 cultivars introduced from the United States Department of Agriculture, were used for genomic DNA analysis (Table 1). All plants were maintained at the National Institute of Horticultural and Herbal Science of the Rural Development Administration, Wanju, South Korea. Total genomic DNA was extracted from the young leaves of blueberries using the DNeasy Plant Mini Kit (Qiagen, Valencia, CA) according to the manufacturer's instructions. The quantity and quality of the DNA obtained were assessed using a NanoDrop (Thermo Scientific, Rockford, IL) and $0.8 \%$ agarose gel electrophoresis. A working solution of $5 \mathrm{ng} \cdot \mu \mathrm{L}^{-1}$ genomic DNA was prepared for PCR analysis.

$R A P D$ analysis. To identify suitable primers for this study, four cultivars (Bluejay, Duke, Pioneer, and Spartan) were tested with 250 Operon (Operon Technologies, Alameda, CA) and UBC (University of British Columbia, Vancouver, BC) primers. We selected 43 PCR primers from data conducted on four cultivars based on their ability to produce clear and repeatable polymorphic bands. These

\footnotetext{
Received for publication 12 May 2017. Accepted for publication 27 July 2017.

This work was carried out with the support of "Cooperative Research Program for Agriculture Science \& Technology Development (Project No. PJ01022805)" Rural Development Administration, Republic of Korea.

${ }^{1}$ Corresponding author. E-mail: khc7027@korea. kr.
} are most suitable and reliable for identifying cultivars (Powell et al., 1996). Representative techniques used for fruit tree species include RAPD, amplified fragment length polymorphisms, single sequence repeats (SSRs), and inter simple sequence repeats (ISSRs) for DNA fingerprinting. The choice of a DNA marker depends on the scale and purpose of cultivar identification; several different DNA 
Table 1. Blueberry cultivars used in this study, including their parentages and types.

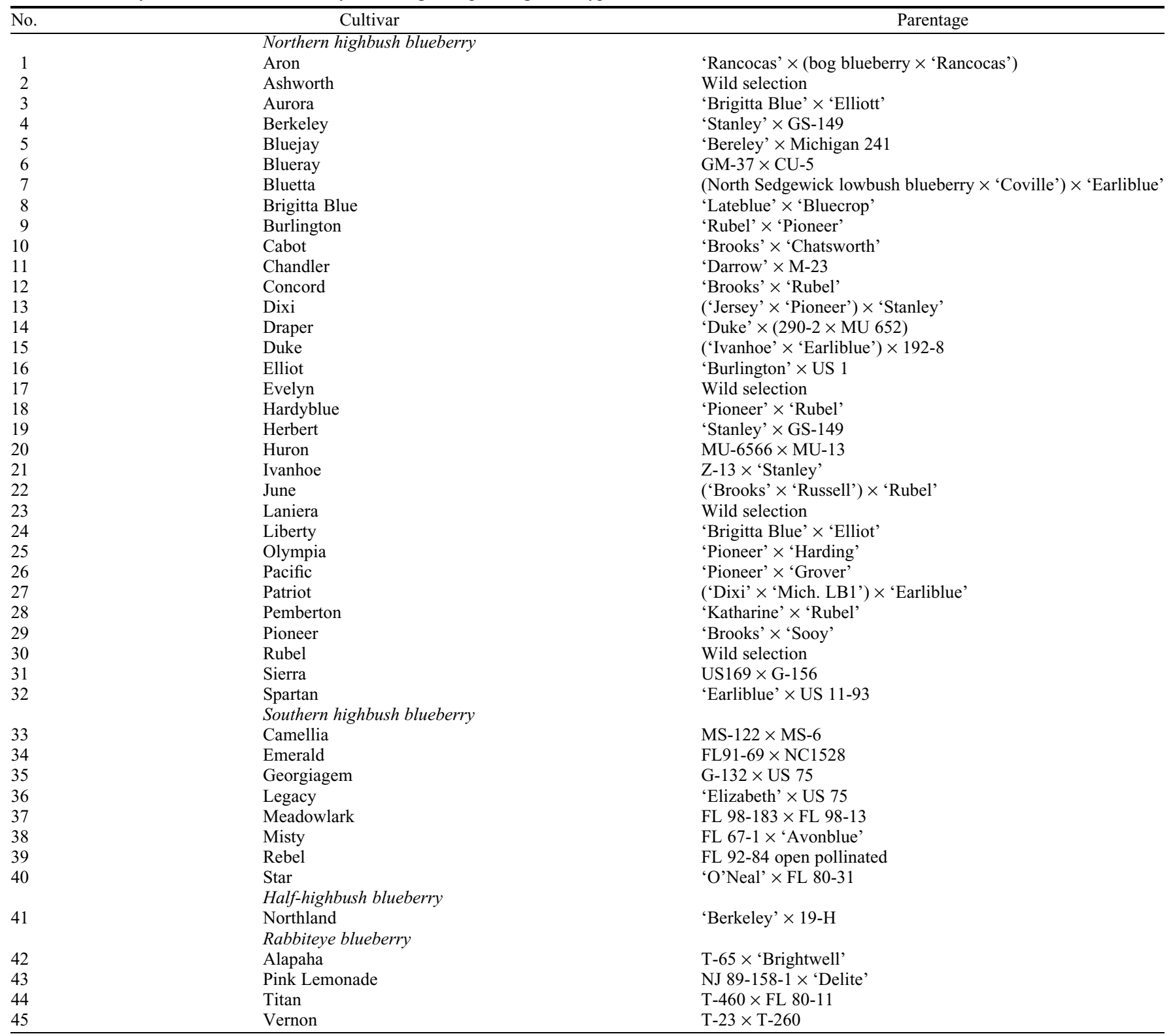

primers were used to obtain genotype-specific RAPD markers. PCR reactions for RAPD were performed in a $12.5-\mu \mathrm{L}$ reaction mixture containing $20 \mathrm{ng}$ template DNA, $1 \times$ PCR buffer, $0.36 \mu \mathrm{M}$ random primer, $200 \mu \mathrm{M}$ each of deoxynucleoside triphosphates (dNTPs: dATP, dTTP, dGTP, and dCTP), 3 mM $\mathrm{MgCl}_{2}$, and 0.5 units of Taq DNA polymerase (Genetbio, Daejeon, South Korea). Amplifications were performed in a thermal cycler $(\mathrm{C} 1000$; Bio-Rad Laboratories, Hercules, CA) with the following cycle parameters: initial denaturation at $94{ }^{\circ} \mathrm{C}$ for $4 \mathrm{~min}$; 10 cycles of denaturation at $94{ }^{\circ} \mathrm{C}$ for $45 \mathrm{~s}, 37^{\circ} \mathrm{C}$ for $45 \mathrm{~s}$, and $72{ }^{\circ} \mathrm{C}$ for $2 \mathrm{~min}$; and then 35 cycles of denaturation at $94{ }^{\circ} \mathrm{C}$ for $45 \mathrm{~s}, 42{ }^{\circ} \mathrm{C}$ for 45 $\mathrm{s}$, and $72{ }^{\circ} \mathrm{C}$ for $2 \mathrm{~min}$. The final extension was at $72{ }^{\circ} \mathrm{C}$ for $10 \mathrm{~min}$. The amplified products were analyzed with $1.4 \%$ agarose gel electrophoresis in $0.5 \times$ Tris-borate-EDTA buffer (45 mm Tris-borate, $1 \mathrm{~mm}$ EDTA, $\mathrm{pH}$ 8.0) at $150 \mathrm{~V}$ for $3 \mathrm{~h}$ and visualized by ultraviolet illumination after ethidium bromide staining. The amplified bands for all individuals were then scored as 1 (present) or 0 (absent) to determine genetic relationships. Genetic similarity was estimated using a simple matching coefficient (Sokal and Michener, 1958) and MultiVariate Statistical Package Ver. 3.13 (Kovach Computing Services, Wales, UK). A dendrogram was constructed by cluster analysis using the unweighted pair group method of arithmetic averages (UPGMA).

Cloning of RAPD fragments and sequencing. Selected cultivar-specific RAPD bands were excised with a sterile cutter from agarose gel. The extracts were purified with a QIAquick Gel Extraction Kit (Qiagen) and cloned into the pCR2.1-TOPO vector with a TOPO TA Cloning Kit (Invitrogen, Carlsbad, CA). After cloning, five white colonies from each transformation were selected and cultured overnight in $5 \mathrm{~mL}$ Luria-Bertani liquid medium (trypton $10 \mathrm{~g} \cdot \mathrm{L}^{-1}, \mathrm{NaCl} 5$ $\mathrm{g} \cdot \mathrm{L}^{-1}$, and yeast extract $5 \mathrm{~g} \cdot \mathrm{L}^{-1}$ ) containing $100 \mu \mathrm{g} \cdot \mathrm{mL}^{-1}$ ampicillin. Plasmid DNAs were isolated using a QIAprep-spin Plasmid Miniprep Kit (Qiagen) and sequenced on an $\mathrm{ABI}$ 3730xl DNA analyzer (Applied Biosystems, Foster City, CA).

Designing of SCAR primers and PCR analysis. Based on sequence data, specific primers (22-27 mer) were designed using Primer3Plus (http://www.bioinformatics.nl/ cgi-bin/primer3plus/primer3plus.cgi/). Some of these primers included the original 10-mer sequence of the RAPD primer used for amplification. For each RAPD marker, four oligonucleotides were designed for use as SCAR primers. PCR was used to amplify cultivarspecific bands in a $15-\mu \mathrm{L}$ reaction mixture of 20 ng template DNA, $1 \times$ PCR buffer, $0.5 \mu \mathrm{M}$ forward and reverse primers, $200 \mu \mathrm{M}$ of each dNTP, and 0.5 units of Hot Start Taq DNA polymerase (Genetbio). The amplifications 
were performed with initial denaturation at $94{ }^{\circ} \mathrm{C}$ for $10 \mathrm{~min}$; followed by 30 cycles at $94{ }^{\circ} \mathrm{C}$ for $30 \mathrm{~s}, 63$ to $65^{\circ} \mathrm{C}$ for $30 \mathrm{~s}$, and $72{ }^{\circ} \mathrm{C}$ for $1 \mathrm{~min}$; and final extension at $72{ }^{\circ} \mathrm{C}$ for 5 $\mathrm{min}$. The SCAR products were resolved electrophoretically in a $1.4 \%$ agarose gel.

\section{Results and Discussion}

Screening of specific RAPD fragments. We observed different polymorphic bands in
43 random primers used in the RAPD analysis of 45 blueberry cultivars. In total, 210 distinct markers (200-1200 bp) were obtained from the RAPD analysis. The results obtained for each random primer are summarized in Table 2 . The number of polymorphic bands ranged from three to eight, with five bands generated per primer on average. Five random primers (OPA-19, OPR-12, OPR-16, OPU-07, and UBC424) generated seven to eight discrete reproducible bands, whereas

Table 2. Random amplified polymorphic DNA primers used in this study, their sequences, and the numbers of polymorphic fragments produced.

\begin{tabular}{|c|c|c|c|}
\hline No. & Primer & Sequence $\left(5^{\prime} \rightarrow 3^{\prime}\right)$ & $\begin{array}{l}\text { No. of polymorphic } \\
\text { fragments produced }\end{array}$ \\
\hline 1 & OPA-09 & GGGTAACGCC & 3 \\
\hline 2 & OPA-15 & TTCCGAACCC & 4 \\
\hline 3 & OPA-16 & AGCCAGCGAA & 4 \\
\hline 4 & OPA-19 & CAAACGTCGG & 7 \\
\hline 5 & OPB-08 & GTCCACACGG & 5 \\
\hline 6 & OPC-20 & ACTTCGCCAC & 4 \\
\hline 7 & OPE-12 & TTATCGCCCC & 4 \\
\hline 8 & OPE-17 & CTACTGCCGT & 5 \\
\hline 9 & OPF-07 & CCGATATCCC & 5 \\
\hline 10 & OPF-13 & GGCTGCAGAA & 6 \\
\hline 11 & OPG-09 & CTGACGTCAC & 4 \\
\hline 12 & OPG-10 & AGGGCCGTCT & 3 \\
\hline 13 & OPH-20 & GGGAGACATC & 4 \\
\hline 14 & OPK-17 & CCCAGCTGTG & 4 \\
\hline 15 & OPK-19 & CACAGGCGGA & 5 \\
\hline 16 & OPL-02 & TGGGCGTCAA & 4 \\
\hline 17 & OPL-12 & GGGCGGTACT & 6 \\
\hline 18 & OPM-13 & GGTGGTCAAG & 6 \\
\hline 19 & OPM-18 & CACCATCCGT & 4 \\
\hline 20 & OPN-03 & GGTACTCCCC & 4 \\
\hline 21 & OPN-07 & CAGCCCAGAG & 4 \\
\hline 22 & OPN-19 & GTCCGTACTG & 5 \\
\hline 23 & OPQ-04 & AGTGCGCTGA & 3 \\
\hline 24 & OPR-09 & TGAGCACGAG & 4 \\
\hline 25 & OPR-12 & ACAGGTGCGT & 7 \\
\hline 26 & OPR-16 & CTCTGCGCGT & 8 \\
\hline 27 & OPU-02 & CTGAGGTCTC & 5 \\
\hline 28 & OPU-07 & CCTGCTCATC & 7 \\
\hline 29 & OPW-11 & CTGATGCGTG & 4 \\
\hline 30 & OPY-11 & AGACGATGGG & 4 \\
\hline 31 & OPY-13 & GGGTCTCGGT & 4 \\
\hline 32 & OPY-17 & GACGTGGTGA & 5 \\
\hline 33 & UBC 168 & CTAGATGTGC & 6 \\
\hline 34 & UBC190 & AGAATCCGCC & 6 \\
\hline 35 & UBC256 & TGCAGTCGAA & 5 \\
\hline 36 & UBC268 & AGGCCGCTTA & 4 \\
\hline 37 & UBC297 & GCGCATTAGA & 6 \\
\hline 38 & UBC320 & CCGGCATAGA & 6 \\
\hline 39 & UBC333 & GAATGCGACG & 4 \\
\hline 40 & UBC424 & ACGGAGGTTC & 7 \\
\hline 41 & UBC504 & ACCGTGCGTC & 4 \\
\hline 42 & UBC531 & GCTCACTGTT & 5 \\
\hline 43 & UBC550 & GTCGCCTGAG & 6 \\
\hline
\end{tabular}

the OPA-09, OPG-10, and OPQ-04 primers generated three polymorphic bands. Burgher et al. (2002) reported that 11 primers produced 73 polymorphic RAPD bands among 26 lowbush blueberry cultivars. Carvalho et al. (2014) obtained 118 polymorphic bands using 10 selected primers among 10 highbush blueberry cultivars. Thus, the number of polymorphic bands in our study was smaller than those found in similar studies; the different number of polymorphic bands selected might account for using different primers and the genetic diversity in our blueberry cultivars. In this study, unambiguous amplified DNA bands were chosen carefully and scored for cultivar identification to ensure the absence of artifacts. An example of the RAPD patterns generated with the UBC168 primer is shown in Fig. 1. An approximately 590-bp polymorphic band has been amplified from Patriot, Pink Lemonade, and Titan blueberry cultivars. Aruna et al. (1995) developed a cultivar hierarchical key for the identification of 19 rabbiteye cultivars based on 11 RAPD markers amplified from four RAPD primers (OPC12, OPC17, OPG09, and OPG12). ArceJohnson et al. (2002) used two RAPD primers to identify the five most important Chilean highbush cultivars. RAPD analysis can be used to identify many useful polymorphisms rapidly and efficiently, and has tremendous potential for cultivar identification ( $\mathrm{Lu}$ et al., 1996). However, the reproducibility of this technique is affected by many factors, such as experimental conditions (Muralidharan and Wakeland, 1993; Scarano and Rao, 2014). The lack of reproducibility is a pitfall to cultivar identification in routine procedures and to data exchange among laboratories (Büscher et al., 1993). Despite such drawbacks, RAPD is still used widely in cultivar identification and cloning and for genetic analysis of many crops (El-Sayed et al., 2011; $\mathrm{Mu}$ et al., 2012; Yu et al., 2013). Among the polymorphic bands, 55 amplified DNA bands $(<1000 \mathrm{bp})$ were selected as RAPD markers to identify the cultivars and for use in subsequent analyses.

Cluster analysis. A dendrogram was constructed to show genetic relationships among the 45 blueberry cultivars based on RAPD data (Fig. 2). A total of 210 RAPD markers were used to calculate simple matching coefficients for cluster analysis by UPGMA. Genetic similarity coefficient values ranged
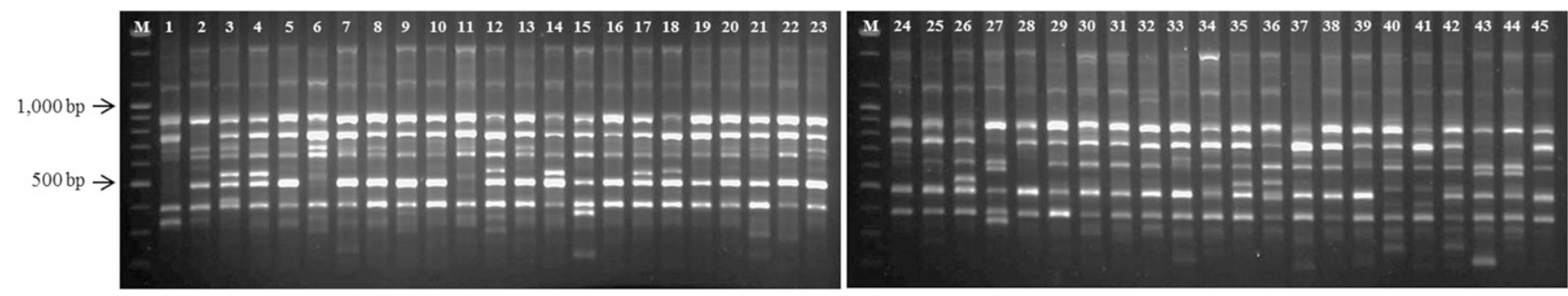

Fig. 1. Random amplified polymorphic DNA profiles of 45 blueberry cultivars amplified using UBC168 primer. Lane numbers represent blueberry cultivars as shown in Table 1. M: 100 bp plus DNA ladder. 


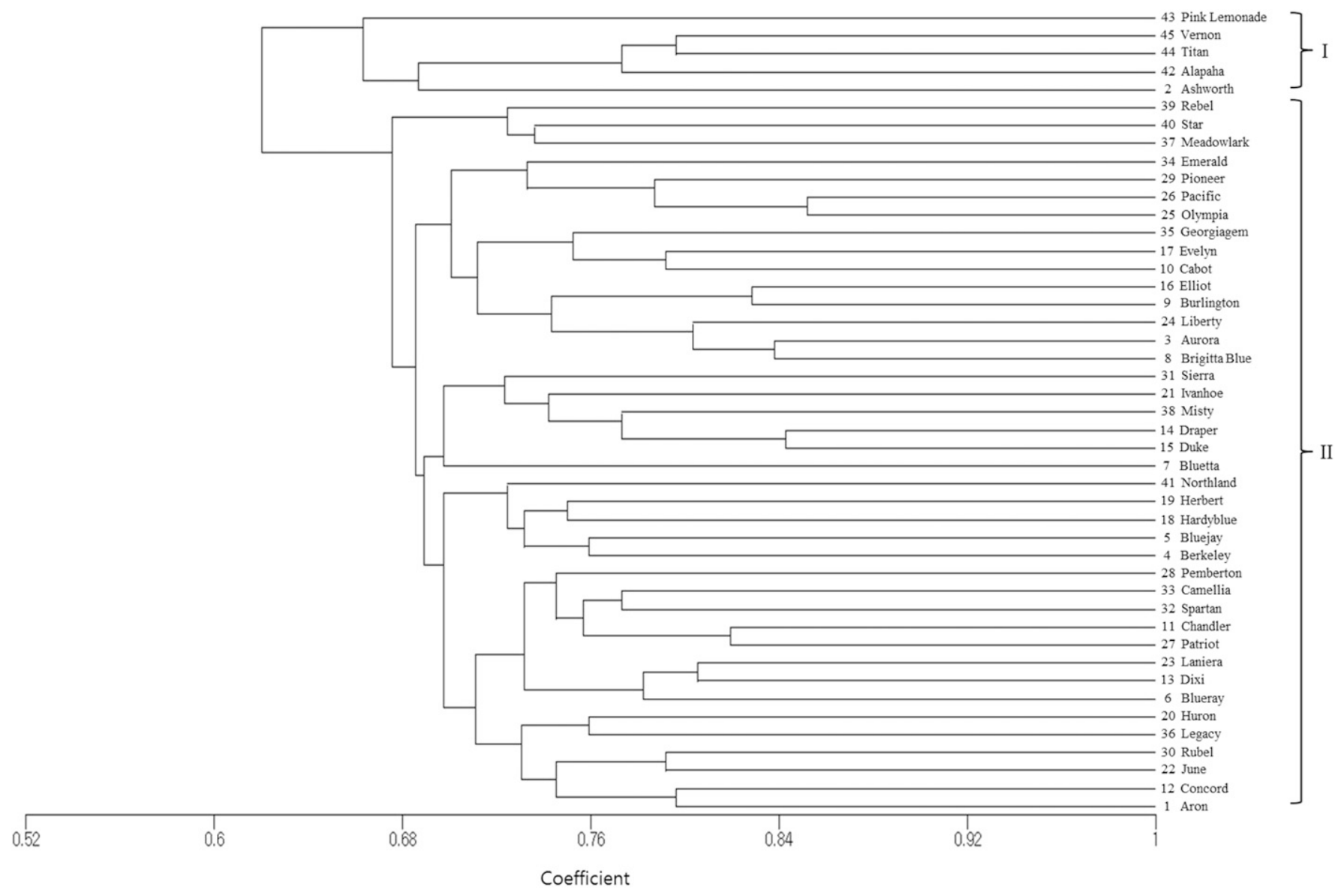

Fig. 2. Dendrogram of 45 blueberry cultivars based on genetic similarity values obtained from random amplified polymorphic DNA data. Scale indicates genetic similarity values.

Table 3. Sequence-characterized amplified region (SCAR) primer pairs derived from cloned random amplified polymorphic DNA (RAPD) marker sequences.

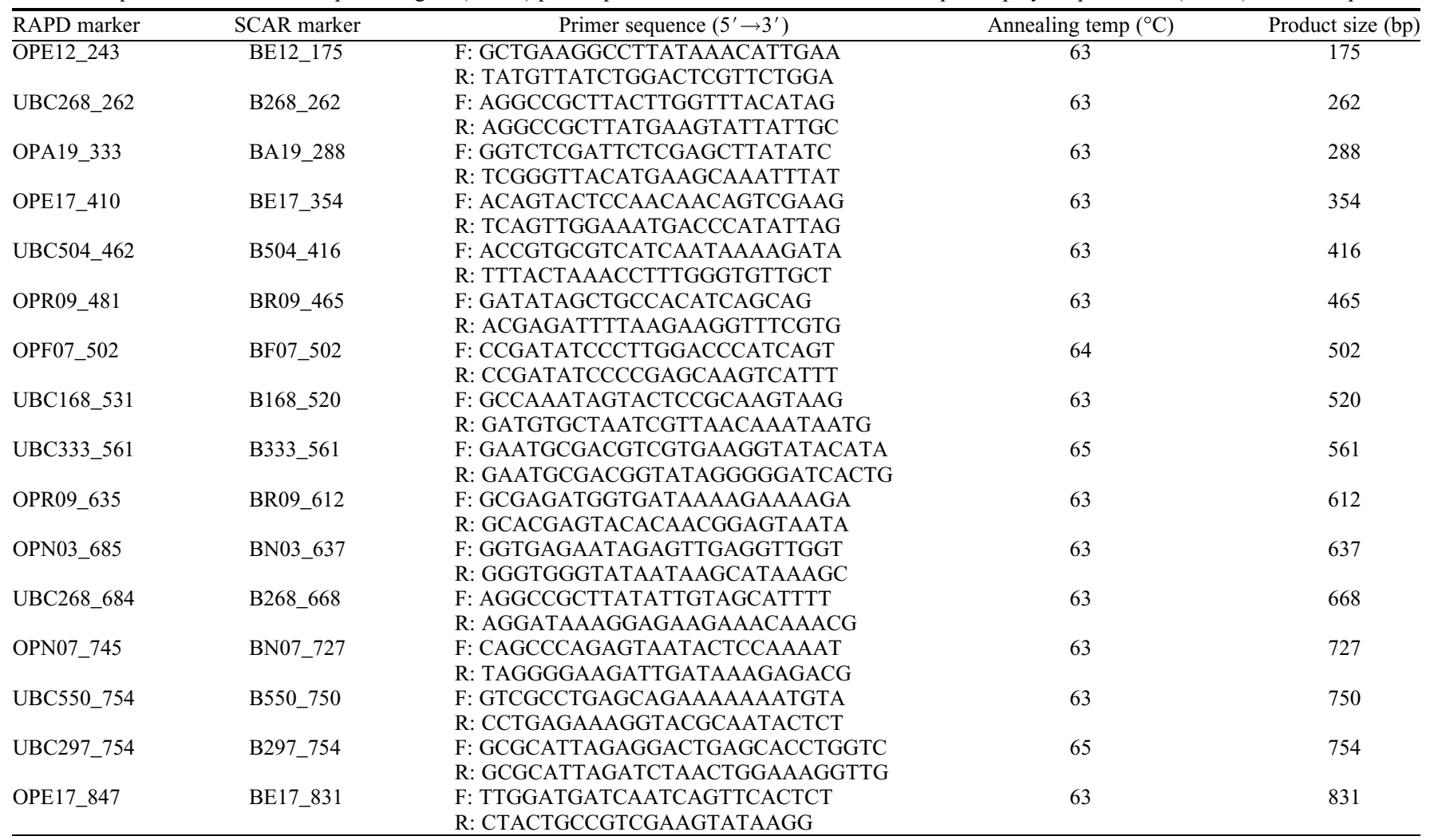

$\mathrm{bp}=$ base pair; $\mathrm{F}$ = forward; $\mathrm{R}=$ reverse. 
from 0.53 to 0.85 , with an average similarity value of 0.68 . The degree of similarity was highest $(0.85)$ between 'Pioneer' and 'Olympia', which is a progeny of 'Pioneer', and lowest $(0.53)$ between the northern highbush cultivar Herbert and the rabbiteye cultivar Vernon. The 45 blueberry cultivars were divided into two clusters with a similarity value of 0.65 . Cluster I consisted of four rabbiteye cultivars (Pink Lemonade, Alapaha, Titan, and Vernon) and the northern highbush cultivar Ashworth. Most commercially important improved rabbiteye cultivars were developed from only four original native selections from the wild (Aruna et al., 1993). Thus, many rabbiteye cultivars are closely related by lineage. 'Ashworth' is a wild selection and has been used as a parent in breeding for hardiness and earliness (Darrow et al., 1960). Bian et al. (2014) used SSR markers to determine that 'Ashworth' clusters near lowbush blueberry accessions and is distinct from other highbush accessions. Cluster II consisted of 31 northern highbush cultivars, eight southern highbush blueberry cultivars, and 'Northland' halfhighbush blueberry cultivar. Among the eight southern highbush blueberry cultivars, Rebel, Star, and Meadowlark clustered together. The northern highbush blueberry cultivars Burlington and Duke clustered with Duke progeny Elliot and Draper, respectively. 'Brigitta Blue' clustered with its progeny 'Aurora' and 'Liberty'. Most blueberry cultivars with common parents clustered together and reflected the genetic contributions of their parentage in the dendrogram. Carvalho et al. (2014) clearly separated 10 highbush blueberry cultivars into northern and southern highbush blueberry types using RAPD and ISSR markers. However, northern and southern highbush blueberry cultivars were not clearly separated in this study, and some southern highbush blueberry cultivars clustered with northern highbush blueberry cultivars. The 'Georgiagem' southern highbush blueberry clustered among the northern highbush blueberry cultivars, as reported previously (Boches et al., 2006). According to Brevis et al. (2008), southern highbush blueberry cultivars exhibit similar levels of molecular relatedness to historical northern highbush blueberry cultivars. Thus, southern highbush blueberry cultivars are less genetically diverse than previously thought. The accuracy of genetic similarity estimates depends on the number of markers analyzed and their distribution within the genome (Messmer et al., 1993). Further study is needed to analyze genetic relationships among blueberry cultivars more precisely using additional RAPD and other markers.
Conversion of selected RAPD fragments into SCAR markers. The sequences of the 55 polymorphic fragments identified in this study were determined to convert RAPD markers into SCAR markers. Based on these sequence data, we synthesized specific primer sets to amplify the internal polymorphic fragment region. Of the 55 reproducible RAPD markers, 16 were converted successfully to more specific dominant SCAR markers. Some primer sets resulted in a failure of PCR amplification, whereas others produced unclear polymorphisms (data not shown). SCAR markers were amplified in a single band and were suitable for presence/ absence screening by agarose gel electrophoresis. The developed SCAR primer sequences, annealing temperature, and amplicon size are summarized in Table 3. The sequence results showed that the UBC333_561 RAPD fragment had a size of $561 \mathrm{bp}$ and contained the original sequences of the UBC333 primer at the ends of the cloned RAPD fragment. These results clearly demonstrated that the cloned fragment was derived from the amplified RAPD product. The SCAR marker derived from the UBC333_561 RAPD fragment was designated B333_561. A 561-bp fragment was amplified in the cultivars Alapaha, Aron, Berkeley, Bluejay, Brigitta Blue, Camellia, Concord, Emerald, Huron, Ivanhoe, Legacy,

Table 4. Result of polymerase chain reaction for 16 sequence-characterized amplified region (SCAR) markers and 45 blueberry cultivars.

\begin{tabular}{|c|c|c|c|c|c|c|c|c|c|c|c|c|c|c|c|c|c|c|c|c|c|c|}
\hline \multirow[b]{2}{*}{ SCAR marker } & \multicolumn{22}{|c|}{ Cultivar no. } \\
\hline & 1 & 2 & 3 & 4 & 5 & 7 & 8 & 9 & 10 & 11 & 12 & 13 & 14 & 15 & 16 & 17 & 18 & 19 & 20 & 21 & 22 & 23 \\
\hline$\overline{\text { BE12_175 }}$ & 1 & 0 & 1 & 0 & 1 & 0 & 0 & 0 & 1 & 0 & 0 & 0 & 0 & 0 & 1 & 1 & 0 & 1 & 1 & 0 & 0 & $\overline{1}$ \\
\hline B268_262 & 0 & 1 & 1 & 0 & 0 & 1 & 1 & 0 & 0 & 1 & 0 & 0 & 1 & 1 & 0 & 0 & 0 & 0 & 1 & 1 & 0 & 0 \\
\hline BA19_288 & 0 & 0 & 0 & 0 & 0 & 1 & 0 & 1 & 0 & 1 & 1 & 1 & 0 & 0 & 1 & 0 & 0 & 1 & 0 & 0 & 0 & 1 \\
\hline BE17_354 & 1 & 1 & 0 & 1 & 1 & 0 & 1 & 1 & 1 & 0 & 1 & 0 & 0 & 1 & 0 & 1 & 1 & 1 & 1 & 1 & 1 & 0 \\
\hline B504_416 & 0 & 0 & 0 & 0 & 0 & 1 & 0 & 0 & 0 & 0 & 0 & 0 & 0 & 0 & 0 & 0 & 0 & 0 & 0 & 0 & 0 & 0 \\
\hline BR09_465 & 1 & 0 & 1 & 1 & 0 & 0 & 0 & 1 & 0 & 1 & 1 & 0 & 1 & 1 & 1 & 0 & 0 & 1 & 1 & 1 & 0 & 1 \\
\hline BF07_502 & 0 & 0 & 0 & 0 & 0 & 0 & 0 & 0 & 0 & 0 & 0 & 0 & 0 & 0 & 0 & 0 & 0 & 0 & 0 & 0 & 0 & 0 \\
\hline B168_520 & 0 & 0 & 0 & 1 & 0 & 0 & 0 & 0 & 0 & 1 & 1 & 0 & 0 & 0 & 0 & 1 & 0 & 1 & 0 & 0 & 0 & 0 \\
\hline B333_561 & 1 & 0 & 0 & 1 & 1 & 0 & 1 & 0 & 0 & 0 & 1 & 0 & 0 & 0 & 0 & 0 & 0 & 0 & 1 & 1 & 0 & 0 \\
\hline BR09_612 & 1 & 1 & 1 & 1 & 0 & 0 & 1 & 1 & 1 & 1 & 1 & 1 & 1 & 1 & 0 & 1 & 1 & 1 & 0 & 1 & 0 & 1 \\
\hline BN03_637 & 1 & 0 & 1 & 0 & 1 & 1 & 1 & 0 & 1 & 0 & 1 & 0 & 0 & 0 & 0 & 1 & 0 & 0 & 0 & 1 & 0 & 0 \\
\hline B268_668 & 1 & 1 & 1 & 0 & 1 & 1 & 1 & 0 & 0 & 1 & 0 & 1 & 0 & 0 & 1 & 0 & 0 & 1 & 1 & 0 & 0 & 1 \\
\hline BN07_727 & 1 & 0 & 0 & 0 & 1 & 1 & 0 & 0 & 0 & 1 & 0 & 1 & 0 & 0 & 0 & 0 & 1 & 1 & 0 & 0 & 0 & 1 \\
\hline B550_750 & 1 & 0 & 0 & 1 & 0 & 0 & 0 & 0 & 1 & 0 & 1 & 0 & 0 & 0 & 0 & 0 & 0 & 1 & 0 & 0 & 0 & 0 \\
\hline B297_754 & 1 & 1 & 0 & 0 & 0 & 0 & 0 & 0 & 1 & 1 & 0 & 0 & 0 & 0 & 0 & 1 & 1 & 0 & 0 & 0 & 0 & 0 \\
\hline BE17_831 & 1 & 0 & 1 & 0 & 1 & 0 & 1 & 1 & 0 & 1 & 1 & 1 & 0 & 0 & 1 & 0 & 0 & 1 & 0 & 0 & 1 & 1 \\
\hline \multirow[t]{2}{*}{ No. of SCAR markers } & 11 & 5 & 7 & 6 & 7 & 6 & 7 & 5 & 6 & 9 & 9 & 5 & 3 & 4 & 5 & 6 & 4 & 10 & 6 & 6 & 2 & 7 \\
\hline & \multicolumn{22}{|c|}{ Cultivar no. } \\
\hline SCAR marker & $\overline{24}$ & 25 & 26 & 27 & 28 & 29 & 30 & 31 & 32 & 33 & 34 & 35 & 36 & 37 & 38 & 39 & 40 & 41 & 42 & 43 & 44 & $\overline{45}$ \\
\hline$\overline{B E 12 \_175}$ & 0 & 0 & 1 & 0 & 0 & 0 & 0 & 1 & 1 & 0 & 1 & 0 & 1 & 0 & 0 & 0 & 0 & 0 & 0 & 0 & 0 & $\overline{0}$ \\
\hline B268_262 & 0 & 0 & 0 & 0 & 0 & 0 & 0 & 0 & 0 & 0 & 0 & 1 & 0 & 1 & 0 & 0 & 1 & 0 & 0 & 1 & 1 & 1 \\
\hline BA19_288 & 1 & 1 & 1 & 1 & 0 & 1 & 0 & 0 & 0 & 0 & 0 & 1 & 0 & 0 & 0 & 0 & 0 & 1 & 0 & 0 & 0 & 0 \\
\hline BE17_354 & 1 & 1 & 0 & 0 & 0 & 1 & 1 & 1 & 1 & 0 & 1 & 0 & 1 & 1 & 1 & 1 & 1 & 1 & 1 & 1 & 1 & 1 \\
\hline B504_416 & 0 & 0 & 0 & 0 & 0 & 0 & 0 & 0 & 0 & 0 & 0 & 0 & 0 & 0 & 0 & 0 & 0 & 0 & 0 & 0 & 0 & 0 \\
\hline BR09_465 & 0 & 0 & 0 & 0 & 0 & 0 & 1 & 1 & 1 & 0 & 1 & 0 & 1 & 0 & 0 & 1 & 1 & 0 & 0 & 0 & 0 & 0 \\
\hline BF07_502 & 0 & 0 & 0 & 0 & 0 & 0 & 0 & 0 & 0 & 0 & 0 & 0 & 0 & 0 & 0 & 0 & 0 & 0 & 1 & 0 & 1 & 0 \\
\hline B168_520 & 0 & 0 & 0 & 0 & 1 & 0 & 0 & 0 & 0 & 0 & 0 & 0 & 0 & 0 & 0 & 0 & 0 & 0 & 0 & 0 & 0 & 0 \\
\hline B333_561 & 0 & 0 & 0 & 1 & 1 & 1 & 1 & 0 & 1 & 1 & 1 & 0 & 1 & 1 & 0 & 0 & 0 & 0 & 1 & 0 & 0 & 0 \\
\hline BR09_612 & 1 & 1 & 1 & 1 & 1 & 1 & 0 & 1 & 0 & 1 & 0 & 0 & 0 & 0 & 1 & 1 & 0 & 1 & 0 & 1 & 0 & 0 \\
\hline BN03_637 & 0 & 0 & 0 & 0 & 0 & 0 & 0 & 1 & 1 & 1 & 1 & 1 & 1 & 1 & 1 & 1 & 0 & 1 & 0 & 1 & 0 & 0 \\
\hline B268_668 & 0 & 1 & 1 & 1 & 0 & 0 & 0 & 1 & 0 & 1 & 0 & 0 & 1 & 1 & 1 & 0 & 1 & 0 & 1 & 1 & 1 & 1 \\
\hline BN07_727 & 0 & 0 & 1 & 1 & 0 & 1 & 0 & 1 & 1 & 1 & 0 & 1 & 1 & 0 & 0 & 1 & 0 & 0 & 0 & 0 & 0 & 0 \\
\hline B550_750 & 0 & 1 & 1 & 0 & 0 & 0 & 0 & 0 & 0 & 0 & 0 & 0 & 1 & 0 & 0 & 1 & 0 & 0 & 0 & 0 & 0 & 0 \\
\hline B297_754 & 0 & 1 & 0 & 1 & 0 & 1 & 0 & 0 & 0 & 0 & 0 & 0 & 0 & 0 & 0 & 0 & 0 & 0 & 0 & 0 & 0 & 0 \\
\hline BE17_831 & 1 & 0 & 0 & 1 & 1 & 0 & 1 & 1 & 1 & 1 & 0 & 0 & 1 & 0 & 0 & 0 & 0 & 0 & 0 & 1 & 0 & 0 \\
\hline No. of SCAR markers & 4 & 6 & 6 & 7 & 4 & 6 & 4 & 8 & 7 & 6 & 5 & 4 & 9 & 5 & 4 & 6 & 4 & 4 & 4 & 6 & 4 & 3 \\
\hline
\end{tabular}

Cultivar numbers are listed in Table 1.

The amplified band was scored as 1 (present) or 0 (absent). 
Meadowlark, Patriot, Pemberton, Pioneer, Rubel, and Spartan using the B333_561 SCAR marker (Table 4; Fig. 3A). Compared with the RAPD marker, the B333_561 marker amplified using a specific primer set was more useful because only the differential DNA was amplified, making the identification of blueberry cultivars easy. Furthermore, the application of stringent PCR conditions that exclude competition between primer binding sites results in reliable and reproducible bands that are less sensitive to reaction conditions. A single polymorphic band of the same size as the RAPD fragment or smaller was amplified by a combination of primers. The B268_668 SCAR marker produced a 668 -bp band in the cultivars Alapaha, Aron, Ashworth, Aurora, Bluejay, Bluetta, Brigitta Blue, Camellia, Chandler, Dixi, Elliot, Herbert, Huron, Laniera, Legacy, Meadowlark, Misty, Olympia, Pacific, Patriot, Pink Lemonade, Sierra, Star, Titan, and Vernon (Table 4; Fig. 3B). The BF07_502 SCAR marker produced a single 502-bp fragment in the cultivars Alapaha and Titan, as expected from the sequence data. The B504_416 SCAR marker was produced only in the Bluetta cultivar. The 16 developed SCAR markers generated two (June cultivar) to 11 (Aron cultivar) bands in the 45 blueberry cultivars (Table 4 ). The Duke cultivar had four bands of B268_262, BE17_354, BR09_465, and BR09_612 SCAR markers. The Spartan cultivar had seven bands of BE12_175,
BE17_354, BR09_465, B333_561, BN03_637, BN07_727, and BE17_831 SCAR markers. A subset of smaller markers is needed for increased efficiency in cultivar identification. The application of 11 SCAR markers (BE12_175, BE17_354, BR09_465, BF07_502, B333_561, BR09_612, BN03_637, B268_668, BN07_727, B550_750, and BE17_831) was sufficient to distinguish the 45 blueberry cultivars according to the present or absent and size of PCR product bands.

Of the 55 RAPD markers sequenced, 16 SCAR markers were developed in this study. Some SCAR primer sets experienced the loss of polymorphism or amplification of multiple bands. The low percentage of SCAR marker conversion $(29 \%)$ was presumably caused by the selection of polymorphic RAPD bands that contained multiple fragments of identical molecular weight in the ethidium bromidestained agarose gels (Paran and Michelmore, 1993). Only reproducible RAPD bands should be selected under high-resolution electrophoresis, and these bands should be cloned and sequenced to allow for the design of specific primers (Bernet et al., 2003). Furthermore, SCAR markers often fail to reveal original polymorphisms because the original RAPD polymorphisms are caused by mismatches in one or more nucleotides at the priming sites. Similar results have been reported in cranberry (Polashock and Vorsa, 2002), apple (Cho et al., 2010) and grapevine
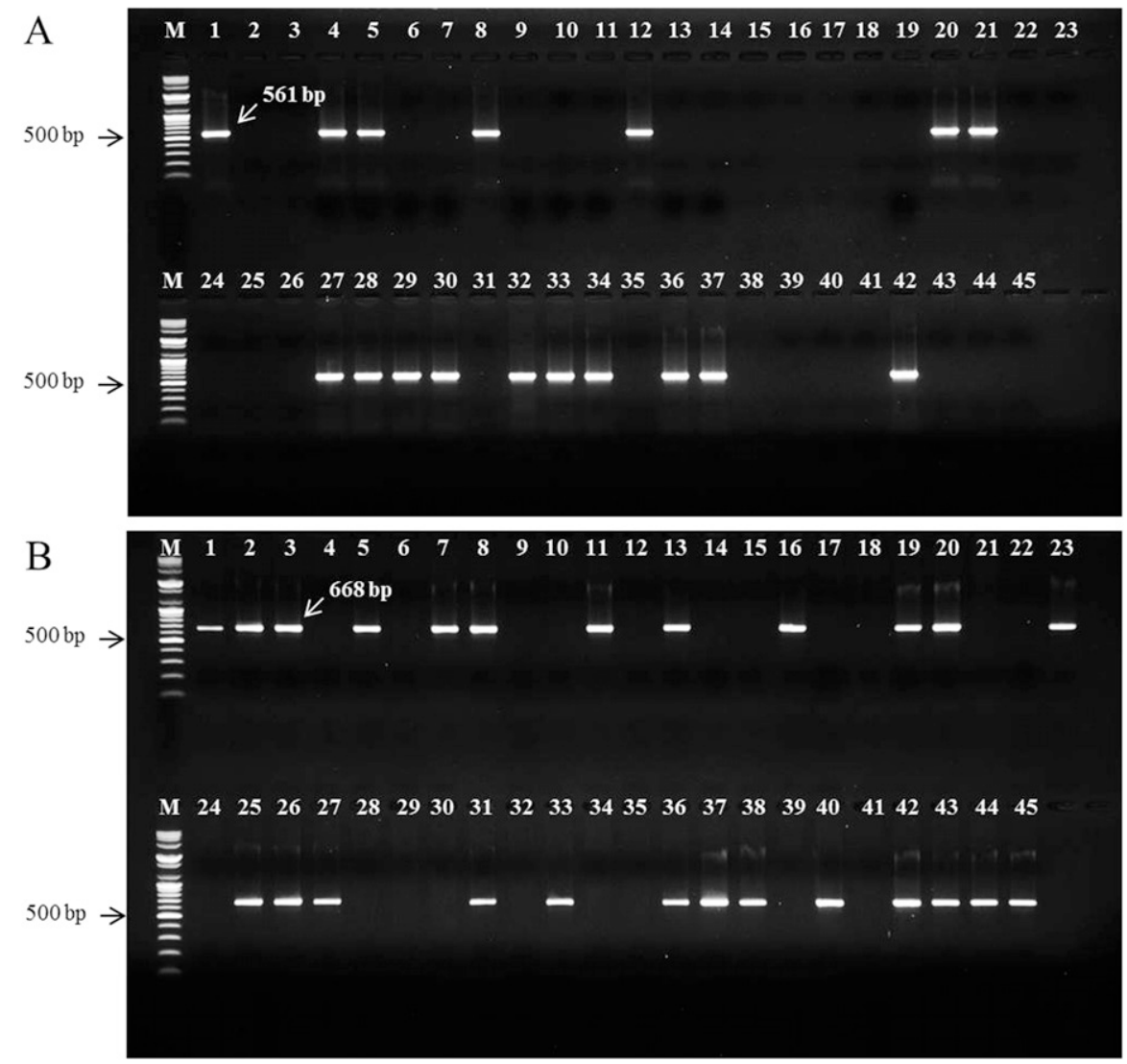

Fig. 3. Amplified fragment patterns of (A) B333_561 and (B) B268_668 sequence-characterized amplified region (SCAR) markers in 45 blueberry cultivars. Arrows indicate SCAR markers. Lane numbers represent blueberry cultivars as shown in Table 1. M: 100 bp plus DNA ladder.
(Vidal et al., 2000) cultivars. Success rates of $\approx 25 \%$ have been reported for the ability of selected RAPD bands to produce useful multiplex SCAR primer sets in cranberry cultivars (Polashock and Vorsa, 2002). Vidal et al. (2000) reported that five putative genotype-specific RAPD markers have been sequenced in grapevine cultivars, and only two primer pairs produced a specific SCAR marker among the 30 sequence-specific primers.

In this study, 16 novel SCAR markers were developed by cloning and sequencing cultivar-specific RAPD bands. A subset of smaller markers was sufficient to identify blueberry cultivars with a high level of accuracy. These SCAR markers can be applied in large-scale screening because they are cost effective, highly reproducible, and easy to use without elaborate electrophoresis methods. We expect that our SCAR markers will complement traditional morphological descriptors used to register new cultivars. The SCAR marker system developed in this study will enable the certification of vegetatively propagated blueberry cultivars.

\section{Literature Cited}

Arce-Johnson, P., M. Rios, M. Zuniga, and E. Vergara. 2002. Identification of blueberry varieties using random amplified polymorphic DNA markers. Acta Hort. 574:221-224.

Aruna, M., M.E. Austin, and P. Ozias-Akins. 1995. Randomly amplified polymorphic DNA fingerprinting for identifying rabbiteye blueberry (Vaccinium ashei Reade) cultivars. J. Amer. Soc. Hort. Sci. 120:710-713.

Aruna, M., P. Ozias-Akins, M.E. Austin, and G. Kochert. 1993. Genetic relatedness among rabbiteye blueberry (Vaccinium ashei) cultivars determined by DNA amplification using single primers of arbitrary sequence. Genome 36:710-713.

Bautista, R., R. Crespillo, F.M. Cánovas, and M.G. Claros. 2002. Identification of olive-tree cultivars with SCAR markers. Euphytica 129:33-41.

Bernet, G.P., S. Bramardi, D. Calvache, E.A. Carbonell, and M.J. Asins. 2003. Applicability of molecular markers in the context of protection of new varieties of cucumber. Plant Breed. 122:146-152.

Bian, Y., J. Ballington, A. Raja, C. Brouwer, R. Reid, M. Burke, X. Wang, L.J. Rowland, N. Bassil, and A. Brown. 2014. Patterns of simple sequence repeats in cultivated blueberries (Vaccinium section Cyanococcus spp.) and their use in revealing genetic diversity and population structure. Mol. Breed. 34:675 689

Boches, P., N.V. Bassil, and L. Rowland. 2006. Genetic diversity in the highbush blueberry evaluated with microsatellite markers. J. Amer. Soc. Hort. Sci. 131:674-686.

Brevis, P.A., N.V. Bassil, J.R. Ballington, and J.F. Hancock. 2008. Impact of wide hybridization on highbush blueberry breeding. J. Amer. Soc. Hort. Sci. 133:427-437.

Burgher, K.L., A.R. Jamieson, and X. Lu. 2002. Genetic relationship among lowbush blueberry genotypes as determined by randomly amplified polymorphic DNA analysis. J. Amer. Soc. Hort. Sci. 127:98-103.

Büscher, N., E. Zyprian, and R. Blaich. 1993. Identification of grapevine cultivars by DNA 
analyses: Pitfalls of random amplified polymorphic DNA techniques using 10-mer primers. Vitis 32:187-188.

Carvalho, M., M. Matos, and V. Carnide. 2014. Fingerprinting of Vaccinium corymbosum cultivars using DNA of fruits. HortScience 4:175-184.

Cho, K.H., S. Heo, H.R. Kim, J.H. Kim, I.S. Shin, S.E. Han, S.E. Kim, and D.H. Kim. 2010. Discrimination of Korean apple cultivars using combination of RAPD-SCAR markers. Kor. J. Hort. Sci. Technol. 28:828-835.

Darrow, G.M., L. Whitton, and D.H. Scott. 1960. The Ashworth blueberry as a parent in breeding for hardiness and earliness. J. Fruit Var. Hort. Digest 14:43-46.

El-Sayed, N.E., M.M. Hashad, and M.M. Shaaban. 2011. Molecular characterization and discrimination among grapevine cultivars by RAPD markers. Austral. J. Basic Appl. Sci. 5:230 235.

Galletta, G.J. and J.R. Ballington. 1996. Blueberries, cranberries, and lingonberries, p. 1107. In: J. Janick and J.N. Moore (eds.). Fruit breeding, Vol. II: Vine and small fruit crops. Prentice Hall, New York, NY.

Goulão, L., L. Cabrita, C.M. Oliveira, and J.M. Leitão. 2001. Comparing RAPD and AFLPTM analysis in discrimination and estimation of genetic similarities among apple (Malus domestica Borkh.) cultivars. Euphytica 119:259-270.

Haghighi, K. and J.F. Hancock. 1992. DNA restriction fragment length variability in the genomes of highbush blueberry. HortScience 27:44-47.

Hernández, P., R. de la Rosa, L. Rallo, G. Dorado, and A. Martín. 2001. Development of SCAR markers in olive (Olea europaea) by direct sequencing of RAPD products: Applications in olive germplasm evaluation and mapping. Theor. Appl. Genet. 103:788-791.

Levi, A. and L.J. Rowland. 1997. Identifying blueberry cultivars and evaluating their genetic relationships using randomly amplified polymorphic DNA (RAPD) and simple sequence repeat- (SSR-) anchored primers. J. Amer. Soc. Hort. Sci. 122:74-78.

Li, G. and Y.-J. Park. 2012. SCAR markers for discriminating species of two genera of medical plants, Liriope and Ophiopogon. Genet. Mol. Res. 11:2987-2996.

Lu, Z.X., G.L. Reighard, W.V. Baird, A.G. Abbott, and S. Rajapakes. 1996. Identification of peach rootstock cultivars by RAPD markers. HortScience 31:127-129.

Messmer, M.M., A.E. Melchinger, R.G. Herrmann, and J. Boppenmaier. 1993. Relationship among early European maize inbreds. II. Comparison of pedigree and RFLP data. Crop Sci. 33:944-950.

Mu, Q., X. Sun, G. Zhong, X. Wang, C. Song, and J. Fang. 2012. Employment of a new strategy for identification of lemon (Citrus limon L.) cultivars using RAPD markers. Afr. J. Agr. Res. 7:2075-2082.

Muralidharan, K. and E.K. Wakeland. 1993. Concentration of primer and template qualitatively affects products in random-amplified polymorphic DNA PCR. Biotechniques 14:362-364.

Paran, I. and R.W. Michelmore. 1993. Development of reliable PCR-based markers linked to downy mildew resistance genes in lettuce. Theor. Appl. Genet. 85:985-993.

Polashock, J.J. and N. Vorsa. 2002. Deveolpment of SCAR markers for DNA fingerprinting and germplasm analysis of American cranberry. J. Amer. Soc. Hort. Sci. 127:677-684.

Powell, W., M. Morgante, C. Andre, M. Hanafey, J. Vogel, S. Tingey, and A. Rafalski. 1996. The comparison of RFLP, RAPD, AFLP, and SSR (microsatellite) markers for germplasm analysis. Mol. Breed. 2:225-238.

Prior, R.L., G. Cao, A. Martine, E. Sofic, J. McEwen, C. O’Brien, N. Lischner, M. Ehlenfeldt, W. Kalt, G. Krewer, and C.M. Mainland. 1998 Antioxidant capacity as influenced by total phenolics and anthocyanin content, maturity and variety of Vaccinium species. J. Agr. Food Chem. 46:2686-2693.

Ratnaparkhe, M.B. 2007. Genome mapping and molecular breeding in plants, p. 217-227. In: C. Kole (ed.). Vol. 4: Fruits and nuts. Univ. Penn. State, PA.

Rowland, L.J. and A.L. Dhanaraj. 2003. Utility of blueberry-derived EST-PCR primers in related Ericaceae species. HortScience 38:1428-1432.

Scarano, D. and R. Rao. 2014. DNA markers for food products authentication. Diversity 6:579596.

Sokal, RR. and C.D. Michener. 1958. A statistical method for evaluating systematic relationships. Univ. Kans. Sci. Bull. 38:1409-1438.

Turkec, A., M. Sayar, and B. Heinze. 2006. Identification of sweet cherry cultivars (Prunus avium L.) and analysis of their genetic relationships by chloroplast sequence-characterised amplified regions (cpSCAR). Genet. Resources Crop Evol. 53:1635-1641.

Vidal, J.R., P. Delavault, M. Coarer, and A. Defontaine. 2000. Design of grapevine (Vitis vinifera $\mathrm{L}$.) cultivar-specific SCAR primers for PCR fingerprinting. Theor. Appl. Genet. 101:1194-1201.

Williams, J.G.K., M.K. Hanafey, J.A. Rafalski, and S.V. Tingey. 1993. Genetic analysis using random amplified polymorphic markers. Methods Enzymol. 218:704-740.

$\mathrm{Xu}$, M., E. Huaracha, and S.S. Korban. 2001. Development of sequence-characterized amplified regions (SCARs) from amplified fragment length polymorphism (AFLP) markers tightly linked to the $V f$ gene in apple. Genome 44 : 63-70.

Yu, M., J. Chu, R. Ma, Z. Shen, and J. Fang. 2013. A novel strategy for the identification of 73 Prunus domestica cultivars using random amplified polymorphic DNA (RAPD) markers. Afr. J. Agr. Res. 8:243-250. 